\title{
17 \\ SIMULATION STUDY OF THE PROCESS PARAMETERS OF A NEW PRECISION GRINDING METHOD
}

\author{
Y. Wang, K. S. Moon and M. H. Miller \\ Department of Mechanical Engineering and Engineering Mechanics \\ Michigan Technological University \\ Houghton, MI 49931, U.S.A.
}

\begin{abstract}
A new method for precision surface grinding which is termed "workpiece modulation" is studied in this paper. Simulations and experiments have shown that workpiece modulation improves ground surface quality. Simulations show that surface texture as quantified by $2 \mathrm{D}$ power spectrum for a single pass with modulation is similar to surface texture from a multiple pass grinding operation without modulation. The effect of process parameters of this new process is analyzed by factorially designed simulations. General rules for selecting grinding process parameters for this new method are given based on the simulation.
\end{abstract}

Grinding, Simulation, Surface Texture.

Keywords

\section{INTRODUCTION}

Grinding process is the common collective name for machining processes which utilize hard abrasive particles as the cutting medium. According to (Malkin, 1989), grinding is a major manufacturing process which accounts for about 20-25\% of the total expenditures on machining operations in industrialized countries. The development of diamond and cubic boron nitride superabrasives, powerful machinery and machining technology has led to a considerably more efficient grinding process. Ground surface quality generally consists of two aspects: surface integrity and surface texture (Malkin, 1989). Surface integrity is associated with mechanical and metallurgical properties of the workpiece and is generally associated with the thermal damage caused by the excessive grinding temperature. Surface texture usually refers to the topography of machined surfaces. The fine-scale topography of ground surfaces shows overlapping cutting scratches in the direction of relative motion between the wheel and workpiece. There are also scallops in the workpiece feed direction which results from runout(Fig.1). Simulations and experiments have demonstrated that in surface grinding the roughness in the cross feed direction is larger than in the feed direction (Domala, 1995). Surface finish has an important role in the wear, lubricating and optical properties of products. Further improvement of the ground surface quality can be done by some non-conventional processes such as electro-polishing and finishing operations such as lapping and polishing; however, this usually involves high cost for the additional machinery and process. 


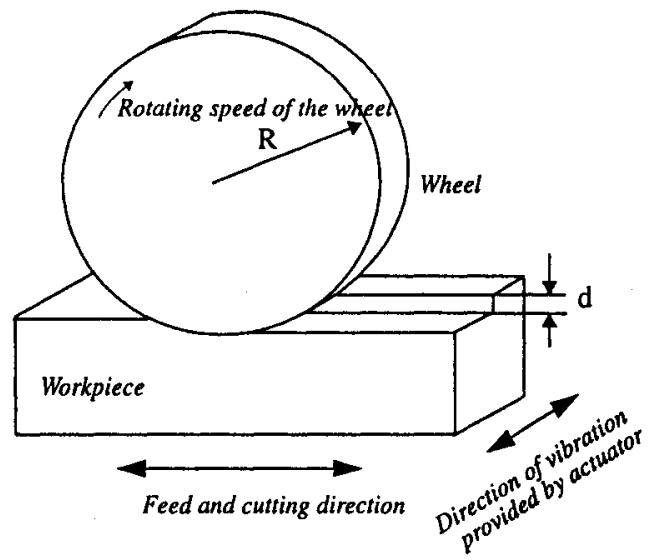

Figure 1 Surface generation in a surface grinding process.

A new method (workpiece modulation) for improving the precision surface grinding quality was proposed recently (Wang, 1996). This method uses high-frequency vibratory movement of the workpiece in its cross feed direction can reduce the surface roughness in this direction and therefore the overall surface roughness. A micro-actuator based workpiece modulation system was implemented on a conventional surface grinding machine (Fig.2). Experimental results show that it offers an effective means of improving the quality of the ground surface texture.

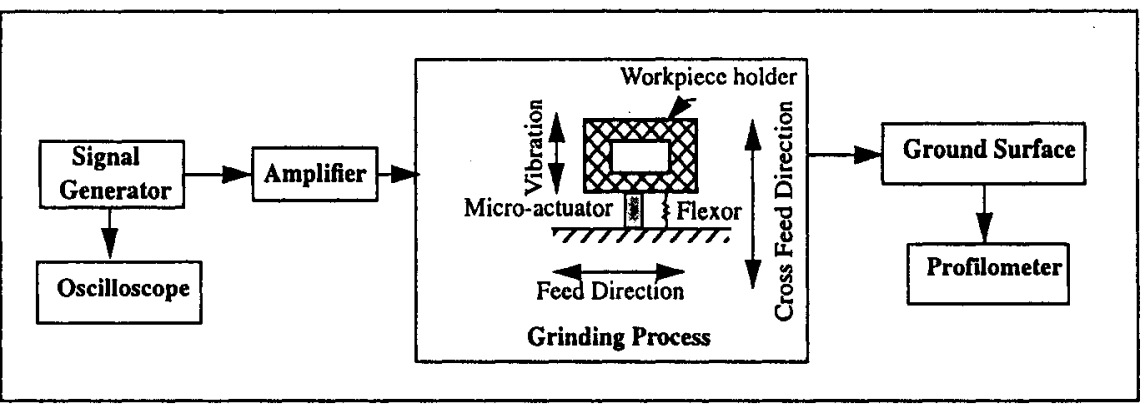

Figure 2 System of workpiece modulation in precision grinding with workpiece actuator.

This paper studies the effect of workpiece modulation on the ground surface quality. The grinding process parameters which are workpiece feed, wheel speed, workpiece modulation frequency and workpiece modulation amplitude are studied by factorial designed experiments through a three dimensional simulation of the grinding process.

\section{Simulation of the workpiece modulation in surface grinding process}

The simulation method in this paper is illustrated in Figure 3. A three dimensional grinding simulation procedure was developed. The output simulation results are 3-D simulated ground surface data. During simulation, each grit on the wheel surface is checked for interference with the workpiece surface. If intereference occurs, the workpiece surface is modified accordingly and the chip thickness, cross sectional area and volume are recorded. At the end of the simulation, the parameters of the average chip geometry and its distribution can be obtained. 


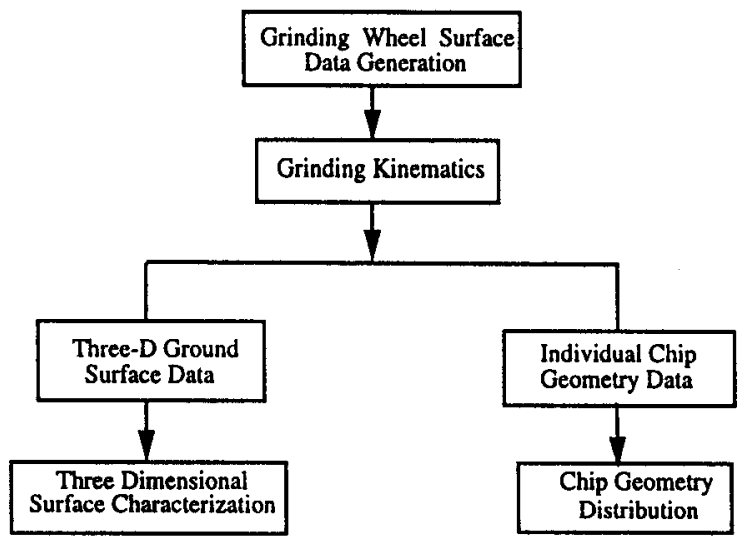

Figure 3 Three dimensional simulation of grinding process

\section{Simulated ground surface characterization}

Simulations were conducted with and without workpiece modulation. The simulated ground surface data are analyzed by 2-D Fourier transformation. The simulated ground surface height data are denoted as $S(x, y)$, and the 2-D FFT can be done by:

$$
F\left(\omega_{p}, \omega_{q}\right)=\frac{1}{M N} \sum_{y=1}^{N} \sum_{x=1}^{M} S(x, y) \cdot e^{-j 2 x\left(\frac{p}{M} x+\frac{q}{N} y\right)}
$$

where: $p=0,1, \ldots M-1 ; q=0,1, \ldots N-1$; are the array coordinates of the surface heights. Correspondingly, $F\left(\omega_{p}, \omega_{q}\right)$ is a matrix of Fourier coefficients, $\omega_{p}$ and $\omega_{q}$ are the angular frequencies in the two orthogonal directions. The power spectrum density or the power associated with each frequency, $P\left(\omega_{p}, \omega_{q}\right)$ can be obtained by:

$$
P\left(\omega_{p}, \omega_{q}\right)=F\left(\omega_{p}, \omega_{q}\right) \cdot F^{*}\left(\omega_{p}, \omega_{q}\right)
$$

where $F^{*}$ is the complex conjugate of $F$. The magnitude of the power will determine the extent of significance of a certain frequency and hence can be used as a measure of relative importance. As reported by Domala et al (Domala, 1995), the spatial dynamics of the wheel and workpiece surfaces are related. Due to the kinematics of the straight surface grinding process (one-dimensional motion in the feed direction), the spectrum of the wheel surface is transformed into a distribution along a line perpendicular to the feed direction on the workpiece spectrum pattern. Further analysis indicates that additional grinding passes cause the power of the ground surfaces to decrease implying that the surface is getting smoother as would be expected.

Figures 4 and 5 show the power spectrum of simulated ground surfaces after a single pass without and with workpiece modulation in the cross direction. It can be seen clearly that introducing workpiece modulation lowers the power spectrum; therefore the ground surfaces are smoother with workpiece modulation than without. In other words, introducing workpiece modulation is similar in benefit as performing multiple-passes. Therefore, this new method has the potential to significantly improve the grinding efficiency. 


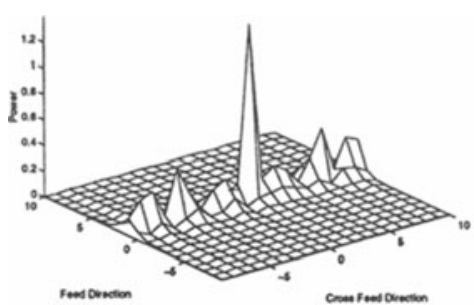

Figure 4 Power spectrum of a ground surface in a single pass without actuation

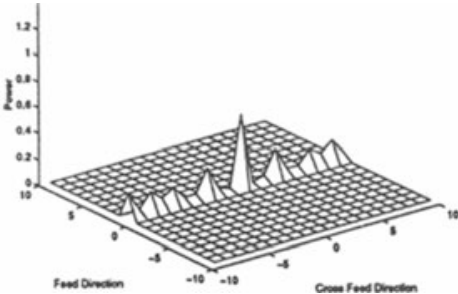

Figure 5 Power spectrum of a ground surface in a single pass with actuation

Generally speaking, surfaces can be classified into homogeneous and inhomogeneous surfaces. The statistical properties of surface texture are invariant with respect to translation of area of examination for homogeneous surfaces. Homogeneous surfaces can be divided into deterministic and random surfaces. The texture of a deterministic surface has strong properties. Current surface evaluation practice is often based on the assumption that a surface in question is homogeneous and deterministic (Chao, 1995).

Based on an understanding of the intrinsic properties of surface topographic features and parameters, a primary three dimensional parameter set was proposed (Dong, 1994). Some of the parameters included in the primary parameter set are extended from their 2-D counterparts; others are specifically defined for characterizing 3-D surface topography. In this paper, we use the following three dimensional parameters similar to those introduced in (Chao, 1995 and Dong, 1994) to characterize the ground surfaces:

\section{Average Surface Height:}

$$
S_{4}=\frac{1}{l_{x} l_{y}} \int_{0}^{d_{x}} \int_{0}^{l_{0}}(|S(x, y)| d x d y)=\frac{1}{M N} \sum_{j=1 i=1}^{N} \sum_{i=1}^{M}\left|S\left(x_{i} y_{j}\right)\right|
$$

where $l_{x}$ and $l_{y}$ are the side lengths of the sampling surface area of concern, $S\left(x_{i} y_{j}\right)$ is the surface height data after substraction of the reference plane (usually a least square plane). This is a parameter similar to the 2-D arithmetic deviation parameter.

Root Mean Square Deviation of Surface Topography:

$$
s_{q}=\sqrt{\frac{1}{l_{x} l_{y}} \int_{0}^{l_{1}} \int_{0}^{l_{1}} s^{2}(x, y) d x d y}=\sqrt{\frac{1}{M N} \sum_{j=1}^{N} \sum_{i=1}^{M} s^{2}\left(x_{i}, y_{j}\right)}
$$

RMS deviation has a definite meaning in statistics, i.e. sample standard deviation, which can also be derived from the autocorrelation function.

Skewness of Topography Height Distribution:

$$
S_{s k}=\frac{1}{s_{q}^{3}} \int_{-\infty} \int_{-\infty} s^{3}(x, y) p(\eta) d x d y=\frac{1}{M N S_{q j}^{3}} \sum_{j=1}^{N} \sum_{i=1}^{M} s^{3}\left(x_{i}, y_{j}\right)
$$

where $p(\eta)$ is the probability density function of the surface $S(x, y)$. Skewness can be used to describe certain aspects of the shape of a topographic height distribution. For a surface which has a symmetric distribution, the skewness is zero. For an asymmetric distribution of topography heights, the skewness is negative if the distribution has a longer tail at the lower side of the mean plane or positive if the distribution has a longer tail at the upper side of the plane. 
Kurtosis of Topography Height Distribution:

$$
S_{k u}=\frac{1}{S_{q}^{4}} \int_{-\infty} \int_{-\infty} s^{4}(x, y) p(\eta) d x d y-\frac{1}{M N S_{q j}^{4}} \sum_{i=1}^{N} \sum_{i=1}^{M} s\left(x_{i} y_{j}\right)
$$

Kurtosis is always presented in conjunction with the skewness to describe the shape of the topography height distribution. It is a measure of the sharpness of the topography height distribution. A Gaussian surface has a kurtosis value of 3. A narrowly distributed topography height distribution has a kurtosis value larger than 3 whereas the kurtosis of a broad height distribution is smaller than 3 .

The simulated ground surfaces with and without workpiece modulation are analyzed using the above four three dimensional surface characterization parameters. The results are documented in Table 1 . It can be seen clearly that vibratory modulation reduces the three dimensional surface roughness both in terms of average surface height and RMS value. The skewness and kurtosis data indicate that the ground surfaces generated with modulation have some sharp peaks above the reference plane and this result needs to be investigated further.

\begin{tabular}{|l||c|c|c|c|}
\hline \multicolumn{1}{|c||}{ Grinding Method } & $S_{\mathrm{a}}$ & $S_{\mathrm{q}}$ & $S_{\text {sk }}$ & $S_{\text {ku }}$ \\
\hline Without Workpiece Modulation & 2.0 & 2.5 & 1.08 & 3.61 \\
\hline With Workpiece Modulation & 1.1 & 1.4 & 1.34 & 4.26 \\
\hline
\end{tabular}

Table 1. Ground surface characterization parameters $(\mu \mathrm{m})$

\section{Chip thickness distribution of the grinding process}

Almost all of the existing grinding chip thickness models are derived in an average sense. The random spacing and itregular shape of grinding grits makes an analytical derivation for chip thickness difficult. These models do not give a distribution of chip thickness and they cannot predict the effect of workpiece modulation on chip thickness; simulation was therefore used. The individual chip thickness is simply calculated by subtracts the current surface height from the previous one at the individual points where cutting happens.

Figures 6 and 7 show the chip size distribution with and without modulation. The distributions are similar although the number of the "small thickness" chips is slightly bigger for workpiece modulation than without. The effect of the process parameters on the average chip thickness will be discussed in the next section.

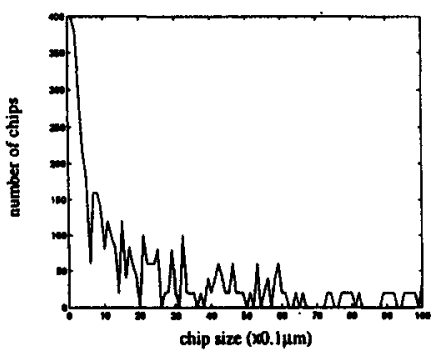

Figure 6 Chip thickness distribution without workpiece actuation

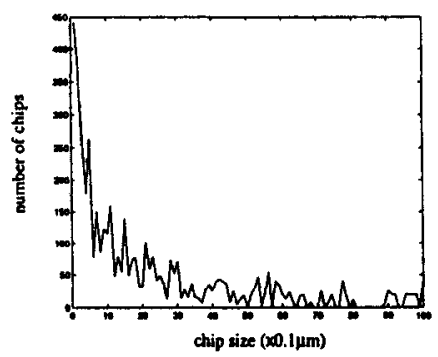

Figure 7 Chip thickness distribution with workpiece actuation

\section{Study of the process parameters by factorially designed experiments}

The experimental design is focused on evaluating the influence of process parameters on surface roughness and chip 
size.

Four process parameters workpiece feed (factor $A$ ), wheel speed (factor $B$ ), workpiece modulation frequency (factor $C$ ) and workpiece modulation amplitude (factor $D$ ) were simulated in a $2^{k}$ factorial design experiment. Sixteen different combinations of the levels of the four process parameters are designed. With the help of normal probability plots, the significant effect of the parameters can be identified. The significant effect of the parameters can also be identified through the analysis of variance (ANOVA) by using Yates' algorithm (Montgometry, 1991).

\section{Surface Roughness:}

The normal probability plot of the residuals of the RMS values of the simulated ground surfaces for different combinations of the grinding parameters is plotted in figure 8. All of the effects that lie along the line are negligible, whereas the large effects are far from the line. The important effects that emerge from this analysis are the main effects $A, B, C$ and the $A B$ interaction. The ANOVA table of this analysis is shown in table 2. At the 0.05 level (which is the $95 \%$ confidence level), the $A, B, C$ and $A B$ have significant effect which agrees with the normal probability plot analysis. The surface roughness increases with an increase in workpiece feed or decrease in wheel speed. Therefore, a favorable approach to increasing production levels while maintaining the required surface finish would be to increase both the workpiece feed and the wheel speed. The frequency of the workpiece modulation frequency (factor C) has significant effect on the surface roughness. The surface roughness decreases with increasing modulation frequency as more grits have the opportunity to impact the same portion of the workpiece. Vibratory movement of the workpiece also has the effect of destroying the scratches generated in previous revolutions. The modulation amplitude is found to be insignificant to the surface roughness in this simulation. The $A B$ interaction effect is plotted in figure 9. It means that at high wheel speeds the surface roughness is less sensitive to changes in feed rate.

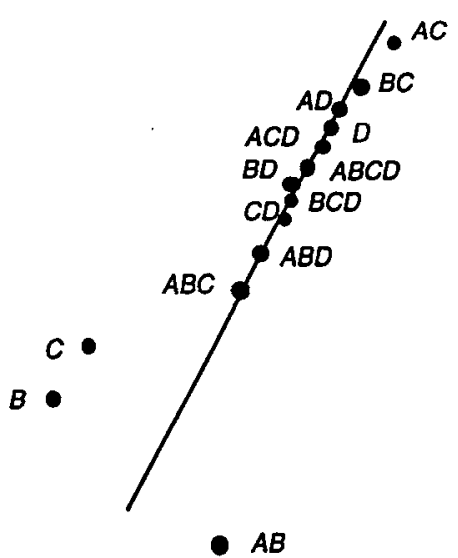

Figure 8. Normal probability plot of residuals for RMS surface roughness
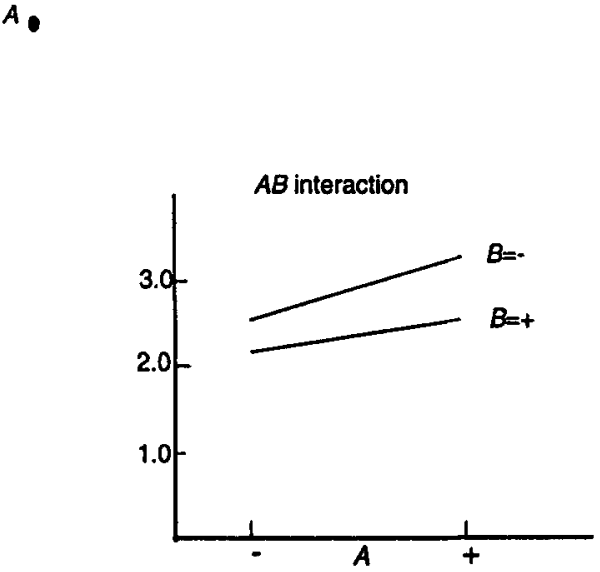

Figure 9 Interaction effect of wheel speed and workpiece feed on surface roughness 


\begin{tabular}{|l||l|c|l|l|}
\hline $\begin{array}{l}\text { Source of } \\
\text { Variation }\end{array}$ & $\begin{array}{l}\text { Sum of } \\
\text { Squares }\end{array}$ & $\begin{array}{l}\text { Degrees of } \\
\text { Freedom }\end{array}$ & $\begin{array}{l}\text { Mean } \\
\text { Square }\end{array}$ & $F_{0}$ \\
\hline$A$ & 2.4025 & 1 & 2.4025 & $40.72\left(^{*}\right)$ \\
\hline$B$ & 0.7225 & 1 & 0.7225 & $12.25\left(^{*}\right)$ \\
\hline$C$ & 0.6400 & 1 & 0.6400 & $10.84\left(^{*}\right)$ \\
\hline$D$ & 0.0025 & 1 & 0.0025 & 0.38 \\
\hline$A B$ & 1.4400 & 1 & 1.4400 & $24.40\left(^{*}\right)$ \\
\hline$A C$ & 0.2025 & 1 & 0.2025 & 3.43 \\
\hline$A D$ & 0.0400 & 1 & 0.0400 & 0.68 \\
\hline$B C$ & 0.0625 & 1 & 0.0625 & 1.06 \\
\hline$B D$ & 0.0100 & 1 & 0.0100 & 0.17 \\
\hline$C D$ & 0.0225 & 1 & 0.0225 & 0.38 \\
\hline$E$ Error & 0.2950 & 5 & 0.0590 & \\
\hline
\end{tabular}

(*): Significant at 0.05 level. $F_{0.05}(1,5)=6.61$

Table 2 ANOVA table for RMS surface roughness

\begin{tabular}{|c||c|c|c|c|}
\hline $\begin{array}{l}\text { Source of } \\
\text { Variation }\end{array}$ & $\begin{array}{l}\text { Sum of } \\
\text { Squares }\end{array}$ & $\begin{array}{l}\text { Degrees of } \\
\text { Freedom }\end{array}$ & $\begin{array}{l}\text { Mean } \\
\text { Square }\end{array}$ & $F_{0}$ \\
\hline$A$ & 0.4029 & 1 & 0.4029 & $149.22\left(^{*}\right)$ \\
\hline$B$ & 0.5948 & 1 & 0.5948 & $220.30\left(^{*}\right)$ \\
\hline$C$ & 0.0114 & 1 & 0.0114 & 4.22 \\
\hline$D$ & 0.0710 & 1 & 0.0710 & $26.30\left(^{*}\right)$ \\
\hline$A B$ & 0.0512 & 1 & 0.0512 & $18.96\left(^{*}\right)$ \\
\hline$A C$ & 0.0017 & 1 & 0.0017 & 0.63 \\
\hline$A D$ & 0.0086 & 1 & 0.0086 & 3.19 \\
\hline$B C$ & 0.0001 & 1 & 0.0001 & 0.04 \\
\hline$B D$ & 0.0223 & 1 & 0.0223 & $8.26\left(^{*}\right)$ \\
\hline$C D$ & 0.0015 & 1 & 0.0015 & 0.56 \\
\hline Brror & 0.0133 & 5 & 0.0027 & \\
\hline
\end{tabular}

$\left({ }^{*}\right)$ : Significant at 0.05 level. $F_{0.05}(1,5)=6.61$

Table 3 ANOVA table for the chip thickness 


\begin{tabular}{|l||c|c|c|c|}
\hline $\begin{array}{l}\text { Source of } \\
\text { Variation }\end{array}$ & $\begin{array}{l}\text { Sum of } \\
\text { Squares }\end{array}$ & $\begin{array}{l}\text { Degrees of } \\
\text { Freedom }\end{array}$ & $\begin{array}{c}\text { Mean } \\
\text { Square }\end{array}$ & $F_{0}$ \\
\hline$A$ & 6.5850 & 1 & 6.5850 & $120.47\left(^{*}\right)$ \\
\hline$B$ & 8.1033 & 1 & 8.1033 & $142.51\left(^{*}\right)$ \\
\hline$C$ & 0.0888 & 1 & 0.0888 & 1.56 \\
\hline$D$ & 1.0784 & 1 & 1.0784 & $18.97\left(^{*}\right)$ \\
\hline$A B$ & 2.0675 & 1 & 2.0675 & $36.36\left(^{*}\right)$ \\
\hline$A C$ & 0.0319 & 1 & 0.0319 & 0.56 \\
\hline$A D$ & 0.3215 & 1 & 0.3215 & 5.65 \\
\hline$B C$ & 0.0074 & 1 & 0.0074 & 0.13 \\
\hline$B D$ & 0.6651 & 1 & 0.6651 & $11.7\left(^{*}\right)$ \\
\hline$C D$ & 0.0147 & 1 & 0.0147 & 0.26 \\
\hline$E$ irror & 0.2843 & 5 & 0.0569 & \\
\hline
\end{tabular}

$(*)$ Significant at 0.05 level. $F_{0.05}(1,5)=6.61$

Table 4 ANOVA table for the chip area

\begin{tabular}{|c||c|c|c|c|}
\hline $\begin{array}{l}\text { Source of } \\
\text { Variation }\end{array}$ & $\begin{array}{l}\text { Sum of } \\
\text { Squares }\end{array}$ & $\begin{array}{l}\text { Degrees of } \\
\text { Freedom }\end{array}$ & $\begin{array}{c}\text { Mean } \\
\text { Square }\end{array}$ & $F_{0}$ \\
\hline$A$ & 1.9097 & 1 & 1.9097 & $289.35\left(^{*}\right)$ \\
\hline$B$ & 1.5029 & 1 & 1.5029 & $227.71\left(^{*}\right)$ \\
\hline$C$ & 0.0856 & 1 & 0.0856 & $12.97\left(^{*}\right)$ \\
\hline$D$ & 0.0376 & 1 & 0.0376 & 5.67 \\
\hline$A B$ & 0.2858 & 1 & 0.2858 & $43.30\left(^{*}\right)$ \\
\hline$A C$ & 0.0806 & 1 & 0.0806 & $12.21\left(^{*}\right)$ \\
\hline$A D$ & 0.0124 & 1 & 0.0124 & 1.88 \\
\hline$B C$ & 0.0114 & 1 & 0.0114 & 1.73 \\
\hline$B D$ & 0 & 1 & 0 & 0 \\
\hline$C D$ & 0.0041 & 1 & 0.0041 & 0.62 \\
\hline Error & 0.0331 & 5 & 0.0067 & \\
\hline
\end{tabular}

$(*)$ : Significant at 0.05 level. $F_{0.05}(1,5)=6.61$

Table 5 ANOVA table for the chip volume 


\section{Chip Geometry}

In order to calculate the chip geometry in terms of chip thickness, chip area and chip volume, the grits of the wheel are assumed to be spherical and the procedure for calculating these parameters are given in (Miller, 1996). The ANOVA table for the chip geometry with the process parameters are shown in table 3 to table 5 .

For the average chip thickness, the main factors that have significant effect are workpiece feed, wheel speed and modulation amplitude. The average chip thickness increases with increasing workpiece feed or decreasing wheel speed. The average chip thickness also increases with increasing modulation amplitude while the modulation frequency does not have a significant effect. The interaction between workpiece feed and wheel speed $(A B)$ and between the wheel speed and modulation amplitude $(B D)$ also have significant effect on chip thickness as shown in figure 10 and figure 11. The factors that affect the chip thickness have similar effect on the chip area, which can be seen from the ANOVA table 4.

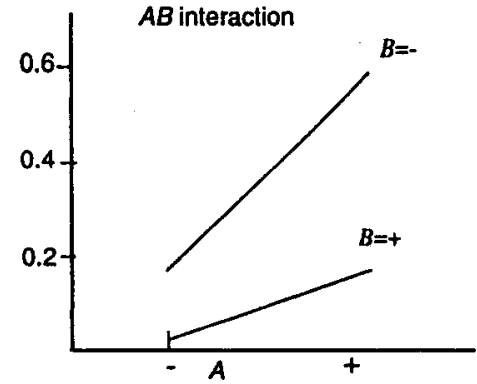

Figure 10 Interaction effect of wheel speed and workpiece feed on chip thickness

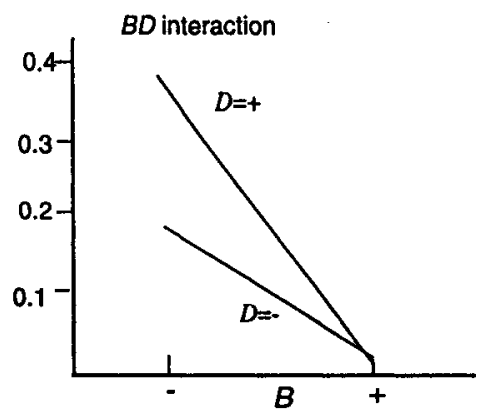

Figure 11 Interaction effect of wheel speed and modulation amplitude on chip thickness

For the average chip volume, the main factors that have significant effect are workpiece feed, wheel speed and modulation frequency. The average chip volume increases with the increase of workpiece feed and decreases with the increase of wheel speed. An increase in modulation frequency generally decreases the average chip volume; however, there is a significant interaction effect between workpiece feed and modulation frequency (figure 12). The interaction between workpiece feed and wheel speed also has significant effect (figure 13).

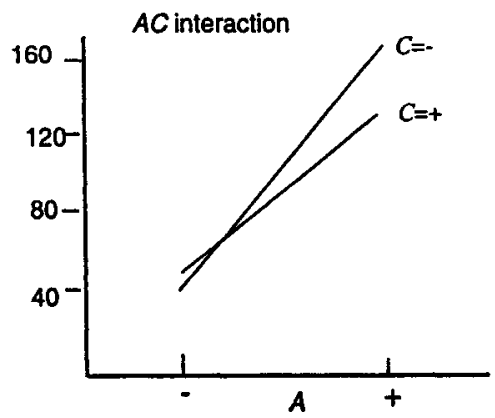

Figure 12 Interaction effect of workpiece feed and modulation frequency on chip volume

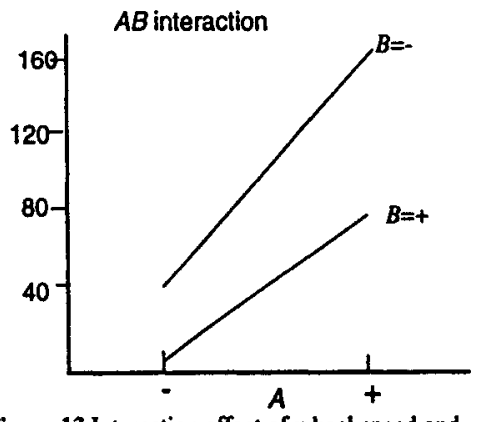

Figure 13 Interaction effect of wheel speed and workpiece feed on chip volume

Based on the statistical analysis, we may conclude that a higher workpiece modulation frequency decreases surface roughness. Chip thickness and chip area do not change significantly with modulation frequency, but are impacted by a change of modulation amplitude. Therefore, for workpiece modulation in grinding, the favorable 
choice of the process parameters are: the wheel speed should be high, the workpiece feed should be slow, the modulation frequency should be high. The statistical analysis indicates that small vibration amplitude is favorable. However, a very small amplitude would be the same as grinding without modulation. Therefore, an optimum exists. Further analysis indicates that the optimum amplitude is approximately the grit radius (fig. 14).

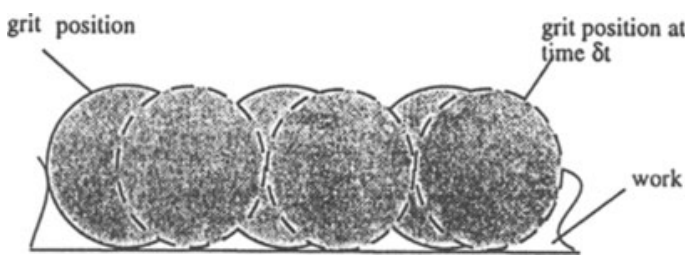

Figure 14 Effect of modulation amplitude.

\section{Conclusions}

A new method for precision surface grinding which is termed "workpiece modulation" is analyzed in this paper. The grinding process is simulated in three dimensions. The simulated ground surface is analyzed using three-dimensional surface parameters. The results show that vibratory modulation in the workpiece cross feed direction can reduce the surface roughness. The grinding process parameters for this new method are analyzed by factorially designed simulations. The results show that for high quality surface grinding, a favorable way in choosing process parameters is: high wheel speed, low workpiece feed rate, high workpiece modulation frequency, the amplitude should be equal to the radius of the grit diameter of the wheel.

\section{References}

Chao, J., G. Zhou, M. C. Leu and E. Geskin. (1995). "Characteristics of Abrasive Waterjet Generated Surfaces and Effects of Cutting Parameters and Structure Vibration." Trans. of ASME, J. of Eng. for Ind. Vol. 117. pp. 516-525. Domala, K. V., K. S. Moon, E. J. Salisbury and J. W. Sutherland. (1995). “A study of the Three-Dimensional Structure of a Ground Surface." Ist Intermational Machining and Grinding Conference. pp.847-863.

Dong, W. P., P. J. Sullivan and K. J. Stout. (1994). "Comprehensive Study of Parameters for Characterizing three dimensional surface topography. III: Parameters for Characterizing Amplitude and Some Functional Properties." Wear. 178. pp. 29-43.

Hahn R. S. and R. P. Lindsay. (1969). "The influence of Process Variables on Material Removal, Surface Finish and Vibration in Grinding." Proc. of the 10th Int'l Mach. Tool Des. and Res. Conf. pp. 677-681.

Malkin, S. (1989). Grinding Technology: Theory and Application of Machining with Abrasives. Ellis Horwood Limited.

Miller, M. H. and K. S. Moon (1996). "The Effect of Workpiece Modulation on Grinding Kinematics." Proceedings of the American Society for Precision Engineering, Spring Topical Meeting.

Miller, M. H. (1994) A Model for the Grinding of Brittle Materials. Ph.D. Dissertation. North Carolina State University, Raleigh, NC.

Montgomery, D. C. (1991).Design and Analysis of Experiments. Third Edition. John Wiley \& Sons, Inc.

Tonshoff, H. K., J. Peters, I. Inasaki and T. Paul. (1992). Modelling and Simulation of Grinding Process. Annals of the CIRP. Vol. 41/2. pp. 677-688.

Wang, Y. ,K. S. Moon and M. H. Miller. (1996) Micro-actuation in Precision Grinding. Proceeding of IMECE. Yoshikawa, H. and T. Sata. (1968). Simulated Grinding Process by Monte Carlo Method. Annals of the CIRP. pp. 297-301.

Younis, M. A. and H. Alawi. (1984). Probabilistic Analysis of the Surface Grinding Process. Tans. of CSME. Vol. 8, No. 4, pp. 208-213. 